\title{
HISTORICAL SOURCES
}

\section{ІСТОРИЧНІ ДЖЕРЕЛА}

DOI: $10.15421 / 272113$

О РОЛИ ГЕНЕРАЛЬНОГО КОНСТРУКТОРА

В. Ф. УТКИНА В ДЕЛЕ СОХРАНЕНИЯ

ДНЕПРОПЕТРОВСКОГО ФИЛИАЛА НАУЧНО-

ИССЛЕДОВАТЕЛЬСКОГО ИНСТИТУТА РЕЗИНОВОЙ

ПРОМЫШЛЕННОСТИ

(Из воспоминаний ветерана (1967-2016) и директора ДФ НИИРП (19872015), лауреата Государственной премии СССР в области науки и техники М. С. ХОРОЛЬСКОГО)

\section{ON THE ROLE OF GENERAL DESIGNER V. F. UTKIN IN THE PRESERVATION OF THE DNEPROPETROVSK BRANCH OF THE SCIENTIFIC RESEARCH INSTITUTE OF THE RUBBER INDUSTRY}

(From the memoirs of a veteran (1967-2016) and director of the DF NIIRP (1987-2015), laureate of the USSR State Prize in the field of science and technology M. S. KHOROLSKY)

Шел 1987 год. Головной институт (Научно-исследовательский институт резиновой промышленности (г. Москва) - сокращенно НИИРП) и все пять его филиалов (Ленинградский, Свердловский, Загорский, Волжский и самый молодой Днепропетровский) готовились к Ученому совету с отчетом за прошедший 1986 год. Как правило, он проходил ежегодно в марте в зале заседаний на пятом этаже в старом корпусе по адресу: Малая Трубецкая, 28, после проверки финансово-хозяйственной деятельности Головного института комиссией Министерства нефтеперерабатывающей и нефтехимической промышленности (Миннефтехимпром СССР), которому подчинялись, и комиссиями Головного института проверки финансово-хозяйственной деятельности всех филиалов. Отчеты делали директора, а в прениях мог участвовать любой член Ученого совета. Ученые советы, на которых я присутствовал с 1974 года в течение 13 лет (я тогда занимал должность начальника конструкторско-технологической лаборатории), всегда проводил директор НИИРП Федюкин Д. Л.

Но накануне в Миннефтехимпроме произошли структурные изменения. Производство резинотехнических изделий (РТИ) на 56 заводах союзного подчинения (а еще практически во всех республиках были заводы республиканского подчинения по производству резиновых, латексных товаров народного потребления, медицинские изделия и др.) решили усилить (было очень много нареканий на качество РТИ) и выделили в отдельную подотрасль (раньше она была объединена вместе с шинной, которую курировал зам. министра Митрофанов Михаил Тимофеевич - 
бывший директор Белоцерковского шинного завода). Заместителем министра по резинотехнической подотрасли был назначен Четвериков Николай Тихонович бывший директор Курского завода РТИ (один из самых крупных заводов бывшего Союза по производству РТИ). Он захотел изучить состояние науки в резиновой промышленности и пожелал принять участие в работе Ученого совета НИИРП и его филиалов. Ученый совет перенесли на начало апреля 1987 года. Я в то время занимал должность заместителя директора по научной работе, сменив на этой должности тяжело заболевшего в 1986 году Евчика Виктора Сидоровича. Директором в тот период был Балашов Адольф Павлович, пришедший в ДФ НИИРП в 1975 году с шинной промышленности не без поддержки Митрофанова М. Т. (они вместе учились в Днепропетровском химико-технологическом институте). А. П. Балашов и М. Т. Митрофанов практически не были знакомы со спецификой разработки и постановки на производство РТИ специального назначения, отличающейся от шинной огромной номенклатурой и малым количеством РТИ в партии, следовательно, низкой производительностью - при единичном и мелкосерийном производстве много операций выполнялось вручную - и многими другими особенностями.

Следует отметить, что перед отъездом в Москву бывший директор ДФ НИИРП Васильев Николай Васильевич (его в 1976 году перевели на работу в Миннефтехимпром) пригласил меня в свой кабинет и сказал:

- Директором будет назначен Евчик Виктор Сидорович. А ты должен, учитывая имеющийся задел, защитить в ближайшее время диссертацию и у тебя еще все впереди. При других обстоятельствах у тебя ничего не получится.

Он по своему опыту это знал. И теперь спустя много лет могу подтвердить - он был прав. Но его прогноз в отношении директора не подтвердился. По непонятным причинам директором был назначен А. П. Балашов, который все время искал повод унизить В. С. Евчика, хотя у В. С. Евчика было больше знаний и опыта разработки РТИ специального назначения. Чтобы унижать В. С. Евчика А. П. Балашов хотел использовать меня, но я отказался от этой роли, прямо сказав ему об этом, чем вызвал с его стороны недовольство.

Как всегда, отчитавшись перед комиссией Головного института, мы заблаговременно подготовили обстоятельный отчет за 1986 год и передали его директору А. П. Балашову. Взяв отчет, он распорядился, чтобы я, главный метролог В. В. Гуляев и начальник материаловедческой лаборатории Л. А. Маркова тоже были на Ученом совете. О том, что Ученый совет будет проводить Н. Т. Четвериков, из нас не знал никто. Об этом нам стало известно только на Ученом совете.

Следует отметить, что продукция ДФ НИИРП отличалась высоким качеством и стабильностью благодаря комплексному подходу при разработке РТИ специального назначения и высокому профессионализму научных работников, конструкторов и технологов, которые всегда подключали метрологов для высококачественного метрологического обеспечения их производства, Этому способствовала грамотная политика директора В. В. Васильева (1969-1976г.г.), которого в 1976 году перевели в Миннефтехимпром. Поэтому в конце 70-х годов на ДФ НИИРП были возложены функции базовой организации по метрологическому обеспечению производства РТИ на всех заводах бывшего Союза. Главным метрологом базовой организации был назначен В. В. Гуляев, который до самой смерти (2018 год) успешно работал в ГП «УНИКТИ «ДИНТЭМ» (новое название - ДФ НИИРП). Следует отметить, что подключаемые специалисты из ВПО «Союзнефтехимавтоматика», которое входило в структуру Миннефтехимпрома, не смогли выявить причины низкого качества РТИ, а поэтому не смогли предложить мероприятия по его повышению.

Обследовав заводы и выявив причины низкого качества многих видов РТИ, нам удалось убедить руководство ВПО «Союзрезинотехника» Миннефтехимпрома (Павлова В. Б. и Васильева Н. В.) в необходимости расширения в ДФНИИРП экспериментальной базы в части создания конструкторско-технологического и производственного блока подразделений метрологического направления. Такую 
поддержку мы получили, и отдача не заставила себя долго ждать. Кроме имеющегося отдела метрологического обеспечения производства РТИ, начали свою работу отделы по разработке нестандартизированных средств измерительной техники (СИТ) и их производства для нужд резинотехнической промышленности. Многие изготовленные приборы проходили проверку при выпуске РТИ специального назначения в ДФ НИИРП, при необходимости оперативно вносились изменения и дальше они отправлялись на заводы РТИ, а также на предприятия других отраслей, что не очень нравилось некоторым конкурентам, в частности НПО «Союзнефтехимавтоматика».

Благодаря внедрению значительного количества рекомендаций по изменению существующих технологических процессов производства РТИ и нестандартизированных СИТ к концу 1986 года удалось резко повысить качество по многим наименованиям РТИ, таких как транспортерные ленты, клиновые ремни, резиновые соски доильных аппаратов, уплотнители тормозных шлангов железнодорожных вагонов, резиноармированные рукава, нашпальные и подрельсовые прокладки и многие другие, которые выпускались в том числе и на Курском заводе РТИ. И не всегда удавалось с начальниками цехов договориться о применении нестандартизированных СИТ. Естественно, в таких случаях мы обращались к Н. Т. Четверикову. Прежде чем принять решение, он глубоко вникал в проблему и лишь после того как убеждался лично, давал соответствующие указания начальникам цехов о необходимости внедрения. А со временем, увидев результаты внедрения разработок в области метрологии, и начальники цехов сами просили о той или иной помощи в разработке и внедрении, что ДФ НИИРПу помогло выжить в 90-е годы.

И вот теперь Ученый совет. Как поведет себя Н. Т. Четвериков в роли зам. министра, мы не знали. После отчетов директоров Головного института Д. Л. Федюкина и ЛФ НИИРП Б. Ф. Гуреева было предоставлено слово директору ДФ НИИРП А. П. Балашову. Мы (В. В. Гуляев, Л. А. Маркова и я, сидевшие рядом в конце актового зала) были сравнительно спокойны за доклад, поскольку результаты по сравнению с другими филиалами у нас были намного лучше, а особых замечаний со стороны руководства Министерства и его ведомств не было. Но как только он дошел до той части, характеризующей результаты научных исследований и новых разработок, в том числе по эластичному опорному шарниру - одному из самых сложных видов РТИ даже на сегодняшний день (об этом изделии Н. Т. Четвериков многое знал и здорово помогал филиалу по обеспечению сырьем), спокойствие наше исчезло мгновенно. Оказывается, наш Отчет о годовой деятельности А. П. Балашов не прочитал, в терминологии путался, многие параметры называл неправильно, какими методами достигается стабилизация прочности нити в резиноармированных рукавах и клиновых ремнях он прочитать не смог. После этого Н. Т. Четвериков задал конкретные три вопроса, на которые он не ответил. Чтобы разрядить обстановку, я попросил слово и ответил на его вопросы, за что он поблагодарил коллектив филиала. Ибо нами действительно была решена очень важная народнохозяйственная задача по спасению сотен тысяч коров, болеющих маститом, внедрив в технологию сборки и проверки параметров доильных аппаратов с помощью разработанного филиалом прибора ПИЧ-1. Но Н. Т. Четверикова мой ответ не удовлетворил, он его ждал от директора. Посмотрев в сторону Д. Л. Федюкина, он прервал заседание Ученого совета и, обращаясь к нему, сказал:

- Это как же надо не уважать себя и своих коллег, чтобы так выступать на Ученом совете? Он же не владеет ситуацией дел в отрасли по метрологическому обеспечению производства РТИ, хотя ДФ НИИРП - базовая организация по этому направлению. Кого Вы поставили руководить филиалом? Руководить научными учреждениями должны профессионалы! Вам это понятно? Пока Вы, Дмитрий Львович, не решите организационно-кадровый вопрос по Днепропетровску, Ученый совет проводить не следует.

Потом наклонился к Д. Л. Федюкину что-то сказал и быстро покинул заседание Ученого совета. 
Стыдно было смотреть друг другу в глаза. К нам подходили коллеги из НИИРП и других филиалов. Одни сочувствовали, другие упрекали за то, что мы не подготовили директора, хотя многие завидовали, что у нашего филиала было много уникальных разработок для отрасли и наших основных заказчиков: КБ «Южное», РКК «Энергия» и их смежники по кооперации, другие предприятия, включая отраслевые.

Некоторые разработки, такие как обтюраторные манжеты для ракет с минометным стартом 15А14 и ее модификаций, уплотнительные устройства для ракет $15 Ж 44$, $15 Ж 52$ и их модификаций, конструкция и технология производства секционных обтюраторно-опорных поясов для ракет $15 Ж 60$ и 15Ж61, уплотнительные устройства для герметизации систем дозаправки орбитальных станций в космосе и другие входили в план новой техники по Миннефтехимпрому. Министерство поощряло указанные разработки. И вдруг такое...

Из шокового состояния вывел громкоговоритель зала заседаний:

- Хорольскому М. С. срочно зайти к Д. Л. Федюкину.

Некоторое время я стоял, не двигаясь. Л. А. Маркова и В. В. Гуляев меня успокаивали:

- Скажи, что мы все, что могли, сделали. И не волнуйся.

Когда я зашел в приемную и спросил у секретаря, кто у директора, она ответила, что никого, но лучше обождать, он очень сердитый. Ситуацию она уже знала. Медленно подошла к двери кабинета, постояла несколько секунд и приоткрыв вторую дверь (первая дверь была открыта) с порога сказала:

- В приемной Хорольский. Пусть заходит?

- Да! Пусть заходит. - услышал я раздраженный голос Федюкина.

Когда я зашел в кабинет, он сидел за столом и пристально смотрел на меня. Лицо было красное и сердитое. Зная его в иной обстановке как жизнерадостного и коммуникабельного человека, его взгляд ничего хорошего не сулил. Ноги перестали слушаться, и я в нерешительности остановился в полутора метрах от его стола. Он слегка привстал и, резко ударив по столу ладонью, так что его настольный календарь подскочил, почти закричал:

- Почему Вы не подготовили директора к докладу?

- Мы ему подготовили доклад и отдали, - был мой сухой ответ.

- Когда Вы ему его дали? - спросил он чуть тише и по всему было видно, что он успокаивается. Медленно он сел на стул за столом совещаний.

- Почти месяц назад, 6 марта, - ответил я. Первый экземпляр находится у него, второй - у меня, третий - у вашего научно-технического отдела. Подписывая у него командировочное удостоверение я напомнил ему о докладе на Ученом совете и он ответил, что доклад уже подготовил для командировки.

Д. Л. Федюкин поднял голову, посмотрел на меня, взял со своего рабочего стола чистый лист бумаги и, протягивая его мне, сказал:

- Чего ты стоишь, садись и пиши заявление.

- Какое? - спросил я в недоумении, не понимая, что я должен писать.

Мгновенно всплыли в памяти два разговора в 1983 и 1986 годах. В 1983 году я защитил диссертацию на соискание ученой степени кандидата технических наук, хотя диссертация была готова к защите еще в 1979 году. Для защиты нужно было заключение Научно-технического совета (НТС) филиала, но А. П. Балашов не ставил этот вопрос в план работы НТС, тянул время. Руководителем моей диссертационной работы был Н. В. Васильев, кандидат технических наук. Время шло, а на НТС мою работу не заслушивали. А тут ВАК изменил правила защиты. Руководителем кандидатской диссертации мог быть только доктор наук. Так мне пришлось менять научного руководителя, и Н. В. Васильев договорился с Д. Л. Федюкиным, что тот будет у меня научным руководителем. Но после того, как я трижды не попал к Д. Л. Федюкину на прием в назначенное время до позднего вечера (у него была сумасшедшая нагрузка), в очередной раз Д. Л. Федюкин выкроил для меня пару минут, чтобы сказать, что он для меня нашел другого научного руководителя (третьего по счету) и что я должен 
к нему подойти, когда тот приедет из командировки. Так моим новым научным руководителем стал доктор технических наук Горелик Борис Моисеевич, работающий в НИИРПе начальником отдела, с которым мы и дошли до финишной «прямой», хоть и не совсем прямой. Учитывая, что А. П. Балашов по отношению ко мне занял обструкционную позицию, было принято решение о моем поступлении в заочную аспирантуру НИИРП, которую я успешно закончил и получил Заключение Ученого совета НИИРП с рекомендацией защиты моей диссертации на специализированном совете в Московском институте тонкой химической технологии имени М. В. Ломоносова, членом которого являлся Д. Л. Федюкин. О моей учебе и защите диссертации в апреле 1983 года в ДФ НИИРП никто, кроме моих двух друзей, не знал до получения мною диплома кандидата наук в сентябре того же года. Когда А. П. Балашов узнал об этом, вместо поздравления я от него получил крепкую пощечину, на которую я отвечать не стал. До конца года мое заявление о пересмотре моего оклада он так и не удовлетворил. И в день получения диплома Д. Л. Федюкин и Н. В. Васильев предложили мне должность директора Свердловского филиала НИИРП, от которой я, не задумываясь, отказался. Они обиделись, но все обошлось.

В 1985 году началась перестройка и пошла мода на выборы директора. Таким выборным со стороны директором, который обещал «золотые горы», стал директор Загорского филиала НИИРП и чуть не уничтожил филиал своими безрассудными действиями. В 1986 году Д. Л. Федюкин предложил мне должность директора Загорского филиала НИИРП, но я снова отказался, сославшись на семейные обстоятельства, на что тот жестко отреагировал:

- Если ты так будешь себя вести, то я и в Днепропетровске тебя найду и вышвырну тебя из нашей системы вообще.

После этого он позвонил Н. В. Васильеву и сказал о моем отказе, надеясь, что Н. В. Васильев сможет повлиять на меня. Но Н. В Васильев на этот раз меня поддержал и директором Загорского филиала НИИРП назначили из своих опытных работников Шпакова Владимира Павловича - великолепного специалиста по надувным резиноармированным инженерным конструкциям. Единственным недостатком у него был пенсионный возраст.

Теперь я оказался в ситуации, которую не я создал, но за которую мне придется отвечать. Мне предложено написать заявление, но не сказано какое. Неужели на увольнение? Я очень любил свою работу, на новые технические решения удалось получить несколько десятков свидетельств на изобретения, в большинстве внедреных. И со всеми заказчиками всегда находили взаимопонимание, а тут «пиши заявление».

Видя мое замешательство, Федюкин Д. Л. твердым голосом сказал:

- Пиши заявление о назначении тебя на должность директора ДФ НИИРП.

Таким предложением я был удивлен и через некоторое время внутреннее напряжение снизилось. Я мог оценивать обстановку и вспомнил процедуру назначения директора предприятия, занимающегося специальной тематикой, о которой нам рассказывал Смирнов Анатолий Георгиевич - зам. директора по кадрам и руководитель аспирантуры НИИРП. Поэтому заявление я писать не стал, а предложил пригласить А. Г. Смирнова и обсудить этот вопрос с ним. Когда А. Г. Смирнов зашел в кабинет, пригласив его присесть, Д. Л. Федюкин спросил:

- Что будем делать с Балашовым А. П.? Кого будем назначать? Твое мнение? Он был с ним на «ТЫ».

- Балашова однозначно надо освобождать, а будущий директор, я думаю, сидит перед нами, - ответил А. Г Смирнов. Если Вы согласны, а я думаю, что М. С. Хорольский именно поэтому здесь и находится, то мне надо ехать в Днепропетровск и решать процедурные вопросы согласования с местными органами.

- Да, ты прав. М. С. Хорольскому я предложил написать заявление на новую должность, а он упирается. Сегодня у нас четверг, вот в понедельник и поезжай в Днепропетровск, - подытожил Дмитрий Львович. 
Согласование прошло сравнительно быстро, причем в районных и городских органах без моего участия (там меня знали по моей общественной работе), а в областных - беседы были продолжительными, так как пришлось обсуждать перспективы развития ДФ ННИИРП. Эти перспективы мы неоднократно обсуждали на Научнотехнических советах, а предложения в правительственные Постановления готовил я лично, согласовывая их с руководством КБ «Южное», которое поддерживало модернизацию ДФ НИИРП и под тематику которого планировалось расширение. Поэтому ситуацию я знал и хорошо представлял, что надо делать. В этот период шло строительство двух корпусов по правительственному Постановлению № 25478: лабораторно-инженерный (78а) и экспериментально-производственный (78б), по которым я готовил технико-экономическое обоснование. Но строительство шло с отставанием и главный инженер Бельский Петр Петрович постоянно ездил к подрядчику (трест № 17), решая вопросы ускорения строительства. Именно по этим основным направлением и шло собеседование.

Так, в апреле 1987 я был назначен исполняющим обязанности директора, а 29 апреля 1987 года был назначен директором ДФ НИИРП. А. П. Балашов остался работать в филиале на должности старшего инженера в Научно-техническом отделе.

Став руководителем ДФ НИИРП, основное внимание я сконцентрировал на расширении экспериментально-производственной и научно-технической базы, выполнении договорных обязательств с заказчиками по разработке новых видов РТИ и поставок опытных партий, разработке и изготовлению нестандартизированных СИТ и метрологическому обеспечению производства РТИ, а также решении социальноэкономических вопросов. За каждое направление отвечало конкретное структурное подразделение, руководителей которых я решил пока не менять - надо присмотреться. Для решения указанных задач часто приходилось ездить в командировки практически по всему бывшему Союзу и часто через Москву.

Вскоре после моего назначения в очередной командировке в Москве в конце лета 1987 года меня разыскал Стогов Владимир Александрович - заместитель начальника отдела разработки нестандартизированных СИТ (начальником отдела был Атаманчук Владимир Николаевич), сказав, что он выполняет поручение Митрофанова М. Т. и предъявил проект приказа Миннефтехимпрома о разделении ДФ НИИРП на две части, который я должен завизировать. В проекте приказа значилось, что одна часть со старым названием ДФ НИИРП, занимающаяся разработкой РТИ, должна подчиняться НИИРП, а вторая часть, занимающаяся разработкой нестандартизированных СИТ, должна подчиняться ВПО «Союзнефтехимавтоматика» с новым названием ДФ НИИРСИТ (Днепропетровский филиал научно-исследовательского института по разработке средств измерительной техники). При этом первая часть за свои средства должна предоставлять сотрудникам второй части жилье, пользование библиотекой, столовой, актовым залом, обеспечивать новому филиалу охрану, содержание зданий и сооружений, выделить складские помещения и др. На обратной стороне стоял ряд согласующих подписей, в том числе: директора ВПО «Союзнефтехимавтоматика», начальника отдела В. Н. Атаманчука, зам. министра М. Т. Митрофанова и др. Прочитав проект приказа, я понимал, что если я его завизирую, то создание на одной территории двух филиалов приведет к уничтожению существующего филиала. У В. А. Стогова я спросил:

- Чья это инициатива по разделению?

В. А. Стогов сделал паузу, а потом ответил:

- Это инициатива М. Т. Митрофанова, поддержанная руководством ВПО «Союзнефтехимавтоматика» и многими другими.

- А В. Н. Атаманчук здесь причем, почему он визирует? - последовал мой следующий вопрос.

- Он планируется на должность директора нового филиала, а я его заместителем, улыбаясь ответил В. А. Стогов.

Я догадался откуда исходит инициатива. Возвращая проект приказа, я сказал, что визировать его не буду. Это приведет к уничтожению ДФ НИИРП. 
- Тогда поехали к М. Т. Митрофанову, - не отставал В. А. Стогов.

- Владимир Александрович, я тебе все сказал: визировать его не буду и ехать никуда не буду, - повернулся и быстро пошел к станции метро, чтобы до отправления вечернего поезда на Днепропетровск с Курского вокзала переговорить с руководством НИИРП, визы которого на проекте приказа не было. Это радовало и вселяло надежду, что можно избежать разделения. Но никого из руководителей НИИРП на месте не оказалось, и я уехал на Курский вокзал.

Кроме того, решил переговорить с В. Ф. Уткиным и попросить его совета. Тем более, что ДФ НИИРП был создан по инициативе Конструкторского бюро «Южное» в 1966 году. Создавая летопись ДФ НИИРП, я знал, что обоснование по этому вопросу по указанию Главного конструктора М. К. Янгеля готовил Преженников Геннадий Владимирович - начальник 447 отдела, в котором находилась группа по отработке РТИ для жидкостных ракетных двигателей, и с которым у меня сложились хорошие дружеские отношения. С ним я очень часто контактировал по обсуждению оптимальных технических решений и всегда находил общий язык.

По приезду я созвонился с Владимиром Федоровичем и попросил его меня принять. Он знал о моем назначении директором и о моем участии во многих принципиально новых разработках. В новой должности у меня с ним встречи не было. Встречу он назначил в тот же день на 14 часов. Предложив мне присесть, он внимательно выслушал мою информацию и тут же попросил секретаря пригласить двух начальников отделов Г. В. Преженникова и Ф. С. Гребенюка из комплекса № 9.

Пока они были в пути, В. Ф. Уткин расспросил как дела в филиале и как продвигаются работы по эластичному опорному шарниру (ЭОШ), разработка которого началась именно по моей инициативе в 1983 году для поворотного сопла ракетного двигателя на твердом топливе (РДТТ), по обтюраторным манжетам и секционном обтюраторно-опорном поясе, конструктивные решения по которым были предложены тоже мной. Работы по наземной экспериментальной отработке обтюраторных манжет и обтюраторно-опорного пояса подходили к концу с хорошими результатами, а по ЭОШ после доработки технологии изготовления арматуры и уточнения некоторых этапов сборки, изготовленные ЭОШи готовились к огневым стендовым испытаниям, которые должны были проводиться в ближайшее время на Павлоградском механическом заводе с участием Днепропетровского филиала НИИ технологии машиностроения (ДФ НИИТМ). С ДФ НИИТМ мы отрабатывали методику проведения испытаний и установления качественных показателей. От результатов испытаний зависела работоспособность РДТТ.

Отвечая на вопросы В. Ф. Уткина, я удивлялся, что он был в курсе дел по работам смежных предприятий. При этом его осведомленность была более чем достаточная для Генерального конструктора - Генерального директора, для которого не было мелочей. Наш разговор прервал телефонный звонок секретарши, которая сообщила, что Г. В. Преженников и Ф. С. Гребенюк в приемной.

- Пусть заходят, - распорядился Владимир Федорович.

Когда они вошли, В. Ф. Уткин вышел из-за стола и после приветственного рукопожатия, предложил им присесть рядом со мной.

- Так вот по чьей милости мы здесь, - здороваясь за руку произнес Г. В. Преженников.

- Рад встрече, давно не виделись, - улыбаясь тряс мою руку Феликс Семенович Гребенюк, с которым я также был знаком по работам с комплексом № 9.

Когда Г. В. Преженников и Ф. С. Гребенюк расположились рядом со мной, Владимир Федорович сказал:

- Наш филиал, который мы создавали для решения задач по созданию и отработки РТИ для ракетно-космической техники, хотят разделить на два филиала, причем вновь создаваемый филиал хотят перепрофилировать и передать в другое ведомство. Я пригласил Вас для того, чтобы в рабочем порядке Вы поработали с Михаилом Степановичем и подготовили для будущего совещания соответствующие проекты рабочих документов о недопущении такого решения. Но самое срочное, что надо сделать, 
я попрошу Вас за моей подписью сегодня подготовить шифровку в Миннефтехипром на имя министра, в которой указать, что вопрос о разделении ДФ НИИРП, созданный по нашей инициативе для разработки и отработки РТИ специального назначения, без представителей КБ «Южное» не рассматривать. И далее подчеркнул, что совещание по указанному вопросу должно быть только с участием представителей КБ «Южное» и ДФ НИИРП.

Обсудив некоторые рабочие моменты и договорившись на следующий день встретиться в филиале с Г. В. Преженниковым и Ф. С. Гребенюком для подготовки проектов рабочих документов, я поблагодарил Владимира Федоровича, извинившись, что отвлек его от решения своих задач, собрался покинуть его кабинет. Он встал из-за стола, попросив своих коллег задержаться, подошел ко мне, пожал руку и, видя мою озабоченность, успокоил, что мол все будет хорошо.

На следующий день к приходу представителей КБ «Южное» я подготовил проект протокола из двух пунктов, причем первый пункт был в дипломатичной форме, что деление филиала нецелесообразно. Но когда коллеги из КБ «Южное» прочитали этот текст сразу в один голос его забраковали и предложили слово «нецелесообразно» заменить на слово «невозможно». А второй пункт оставили без изменения, смысл которого состоял в том, что если возникнет проблема в подключении к работам специалистов ДФНИИРП, то этот вопрос должен решаться на основе договорных отношений в установленном законом порядке. Кроме того, я узнал, что шифровка за подписью В. Ф. Уткина в Миннефтехимпром СССР была отправлена.

Через два дня мне позвонили из Управления новой техники Министерства и пригласили на совещание по вопросу будущего нашего филиала. На мой уточняющий вопрос о теме совещания после некоторого замешательства женский голос сообщил, что совещание будет проводиться по вопросу организации в ДФ НИИРП еще одного филиала. На мой второй вопрос, приглашены ли на планируемое совещание представители КБ «Южное», услышал ответ:

- А при чем здесь КБ «Южное»? Этот вопрос сугубо нашего Министерства и мы его будем решать самостоятельно.

На мой вопрос, кто будет проводить совещание, услышал, что совещание будут проводить заместитель министра М. Т. Митрофанов и начальник Управления новой техники Е. В. Елисеев. Услышав знакомую фамилию друга А. П. Балашова, я понял, что от этого совещания ничего хорошего ждать не приходится и сообщил, что если на этом совещании не будет представителей КБ «Южное», я не приеду. На мой вопрос, почему совещание будет проводить не профильный заместитель министра (нашу подотрасль курировал Н. Т. Четвериков), а М. Т. Митрофанов, услышал ответ:

- Это решение министра и Вас это не касается. Вы должны быть на совещании, которое, учитывая время прибытия Вашего фирменного поезда, назначено на 11 часов.

Услышав эти слова, я сообщил, что, если не будут приглашены представители КБ «Южное» и не будет письменного вызова мне, я не приеду.

- Хорошо, я доложу о нашем разговоре и Вам окончательное решение будет сообщено, - услышал я в трубке, после чего разговор закончился.

После разговора я позвонил Геннадию Владимировичу и подробно передал ему наш разговор. Он выслушал и сказал, что переговорит с В. Ф. Уткиным. А потом я набрал телефон Н. В. Васильева, который работал в то время главным инженером ВПО «Союзрезинотехника», сообщил ему полученную мной информацию и о принятых предварительных мерах. Он уже знал замыслы М. Т. Митрофанова и подтвердил правильность подключения к этой проблеме КБ «Южное», порекомендовал мне сделать все возможное, чтобы не допустить разделения филиала, которому он отдал семь лет своей жизни. Кроме того, он передал мне ставшую ему известной информацию о том, что, когда будет принято решение о разделении ДФ НИИРП, в котором принимает активное участие начальник отдела разработки средств измерений (ОРСИ) В. Н. Атаманчук, его предложат на должность директор будущего филиала. А когда будет принято решение о разделении ДФ НИИРП, то при решении вопроса 
о назначении директора Министерство назначит директором не В. Н. Атаманчука, а А. П. Балашова. Об этом была договоренность у А. П. Балашова с М. Т. Митрофановым.

Поздно вечером того же дня мне позвонил Г. В. Преженников и сказал, что им пришел вызов на совещание и что они с Ф. С. Гребенюком оформляют командировку. Предложили мне ехать вместе с ними, билет они возьмут и мне, на что я согласился. О том, что мне тоже пришел вызов, я узнал на следующий день.

Приехав в Миннефтехимпром бывшего Союза, располагавшееся на улице Гиляровского, 31 , мы узнали, что остальные участники уже прибыли и находятся в одном из залов заседаний, куда нас провели. В совещании, кроме днепропетровской делегации, принимали участие директор НПО «Союзнефтехимавтоматика», заместитель директора НИИРП (Головного института) В. Ф. Ларионов, с которым я был хорошо знаком и который исполнял обязанности Генерального директора (Генеральным директором НИИРП из-за тяжелой болезни Федюкина Д. Л. был назначен Резниченко С. В., но он был в командировке) и еще несколько человек, которых я не знал. В. Ф. Ларионов узнал о совещании в последнюю очередь и не знал некоторых подробностей, поэтому он пригласил меня сесть рядом с ним и ввести в курс дела, что я и сделал. Я оказался за столом напротив Г. В. Преженникова и Ф. С. Гребенюка между В. Ф. Ларионовым и одним из инициаторов разделения ДФ НИИРП - Генеральным директором НПО «Союзнефтехимавтоматика» (фамилию не помню). Я только успел обрисовать В. Ф. Ларионову общую картину, как открылась дверь и в зал заседаний бодрым шагом вошел Е. В. Елисеев, которому зам. министра М. Т. Митрофанов поручил провести совещание, в руках держа какие-то бумаги. Взяв одну из них, он произнес буквально следующее:

- Руководство Министерства поручило мне как начальнику Управления специальных производств Министерства, провести это совещание. Мы пригласили Вас на совещание по вопросу организации в Днепропетровске еще одного филиала на территории ДФ НИИРП. Но поскольку получили какое-то дурацкое письмо от КБ «Южное» за подписью В. Ф. Уткина с требованием без его ведома этот вопрос не рассматривать... - Евгений Владимирович хотел еще что-то сказать, но неожиданно для меня (для всех остальных, я думаю, тоже) поднялся Ф. С. Гребенюк со словами:

- Мы на этом совещании являемся полномочными представителями КБ «Южное» и на него нас командировал Генеральный конструктор - Генеральный директор Герой социалистического труда, академик Уткин Владимир Федорович. Мы считаем, что, назвав его письмо «дурацким», Вы нанесли ему оскорбление в нашем лице. Вы знаете его полномочия как Генерального конструктора? Вы знаете его полномочия как депутата Верховного Совета по оборонной тематике? Вы знаете его полномочия как члена Центрального комитета ЦК КПСС, отвечающего за оборонный комплекс страны?.. - и не дожидаясь ответа продолжал:

- Мы, как полномочные представители Владимира Федоровича, в течение одной минуты ждем от Вас извинений в его адрес. Если этого не последует, мы покидаем данное совещание и забираем с собой М. С. Хорольского с вытекающими отсюда последствиями. Мы ждем, Евгений Владимирович Ваших извинений.

Наступила гробовая тишина. Все были в шоке. На лбу Е. В. Елисеева появились капли пота, лицо покрылось красными пятнами. Мне, сидящему напротив, хорошо было видно пронзительный взгляд Ф. С. Гребенюка, не сводившего глаз с Е. В. Елисеева. Тот посмотрел на Генерального директора НПО «Союзнефтехимавтоматика», который понял с кем имеет дело, молча опустил голову. Секунд через 30-35 наконец он выдавил из себя каким-то чужим голосом:

- Ну я приношу извинения, - и замолчал.

Мгновенно поднялся из-за стола Г. В. Преженников:

- Так Вы приносите извинения или нет? Что означает Ваше «Ну», и если приносите извинения, то кому?

Словно очнувшись, Е. В. Елисеев теперь уже четко своим голосом произнес:

- Я приношу свои извинения Владимиру Федоровичу Уткину в Вашем лице. 
- Извинения принимаются, - произнес Ф. С. Гребенюк и тут же предложил изменить тему совещания. - Мы предлагаем рассмотреть протокол, с которым мы сейчас Вас ознакомим, - и, обращаясь ко мне, попросил раздать экземпляры заготовленного проекта протокола, что я и сделал. Один экземпляр Ф. С. Гребенюк протянул Е. В. Елисееву, который тут же его прочитал. Прочитав проект протокола, соседи справа и слева сказали, что они согласны с текстом протокола и тут же его подписали. Подписали его и мы, и все остальные. Е. В. Елисееву ничего не оставалось делать, как согласиться и закрыть совещание. Попрощавшись, мы покинули зал заседаний и пошли к Н. В. Васильеву. Узнав о результатах совещания, он очень обрадовался и поблагодарил всех за участие. Ф. С. Гребенюк воспользовался телефоном и позвонил В. Ф. Уткину. Владимир Федорович тоже был рад результату и всем высказал благодарность, по словам Феликса Семеновича, «за хорошую работу». Вечером в хорошем настроении с Курского вокзала в 19-00 поездом № 15 мы отправились в родной Днепропетровск.

Так, Владимир Федорович Уткин спас ДФ НИИРП (ныне Государственное предприятие «Украинский научно-исследовательский конструкторско-технологический институт эластомерных материалов и изделий», сокращенно - ГП «УНИКТИ «ДИНТЭМ») от разделения, а точнее - от уничтожения, и это подтвердили все последующие события. В настоящее время ГП «УНИКТИ «ДИНТЭМ» работает в интересах многих предприятий Украины, в том числе Государственного предприятия «Конструкторское бюро «Южное» имени М. К. Янгеля».

Received 27.02.2021

Accepted 05.03.2021 